\title{
Systemic administration of 3-bromopyruvate reveals its interaction with serum proteins in a rat model
}

\author{
Rani Kunjithapatham¹, Jean-Francois H Geschwind ${ }^{1 *}$, Pramod P Rao ${ }^{1}$, Tatiana N Boronina ${ }^{2}$, Robert N Cole ${ }^{2}$ \\ and Shanmugasundaram Ganapathy-Kanniappan ${ }^{1 *}$
}

\begin{abstract}
Background: 3-bromopyruvate (3-BrPA) is a glycolytic inhibitor that affects cancer cells by targeting energy metabolism. Preclinical reports have established that a $1.75 \mathrm{mM}$ dose of 3-BrPA is effective and sufficient to inhibit tumor growth when administered under a loco-regional approach (intraarterial and intratumoral). This loco-regional therapeutic dose was found to be nontoxic when given systemically as well. Yet, the mechanism underlying this lack of toxicity of $1.75 \mathrm{mM} 3-B r P A$ during systemic delivery is unknown. Here, we investigated the mechanism associated with the lack of organ toxicity when $1.75 \mathrm{mM}$ 3-BrPA was administered systemically using radiolabeled $\left({ }^{14} \mathrm{C}\right)-3-B r P A$ in Sprague-Dawley rats.

Findings: Data obtained from tissue-autoradiography of rats infused with ${ }^{14} \mathrm{C}-3$-BrPA showed strong ${ }^{14} \mathrm{C}$-signal in tissue sections of various organs except the brain corroborating that 3-BrPA does not cross the blood-brain barrier. Significantly, Hematoxylin \& Eosin staining and apoptosis assay of tissue sections positive for ${ }^{14} \mathrm{C}$-signal showed no signs of toxicity or apoptosis. Convincingly, the ${ }^{14} \mathrm{C}$-signal observed in tissue-autoradiography emanates from 3-BrPA that is non-reactive or non-toxic, hence we further investigated whether the lack of toxicity is due to its interaction or alkylation with serum components. Analysis of serum proteins by 1D and 2D-gel electrophoretic autoradiography showed that ${ }^{14} \mathrm{C}$-BrPA selectively binds to peptides of molecular mass $\sim 50-60 \mathrm{kDa}$. Mass spectrometry data suggested that ${ }^{14} \mathrm{C}$-BrPA could interact with alpha1-antitrypsin and a peptide of albuminoid-family.
\end{abstract}

Conclusion: Our data indicate that selective interaction of 3-BrPA with serum proteins could contribute to the apparent lack of tissue-toxicity at the indicated close when the drug is given systematically in Sprague-Dawley rats.

Keywords: 3-bromopyruvate, LC-MS/MS, Alpha1 antitrypsin, 2D gel electrophoresis

\section{Findings}

\section{Background}

Recent reports have demonstrated the therapeutic potential of targeting energy metabolism in cancer cells [1-3]. Consequently, research on potent inhibitors of (aerobic) glycolysis, a major energy producing pathway, has gained renewed interest [4]. The pyruvate analog, 3 -bromopyruvate (3-BrPA) is a glycolytic inhibitor that affects cancer cells by disrupting energy metabolism

\footnotetext{
* Correspondence: jfg@jhmi.edu; gshanmu1@jhmi.edu

'Russell H. Morgan Department of Radiology and Radiological Sciences, Johns Hopkins University School of Medicine, 600 N. Wolfe Street, Baltimore, MD 21287, USA

Full list of author information is available at the end of the article
}

[5]. Studies from our laboratory and others have identified the principal intracellular targets and molecular mechanisms involved in 3-BrPA's antitumor effects [6-8]. 3-BrPA irreversibly alkylates the glycolytic enzyme, glyceraldehyde-3-phosphate dehydrogenase (GAPDH) resulting in the disruption of glucose metabolism leading to cell death. Several studies have demonstrated the therapeutic advantage of 3-BrPA against different types of cancers, in vitro and in vivo [9-15]. Further investigations on animal tumor models demonstrated that $1.75 \mathrm{mM} 3$-BrPA is the effective therapeutic dose for treating liver cancer through loco-regional approaches such as intra-arterial (IA) or intratumoral deliveries $[14,16]$. Thus, substantial preclinical data and a

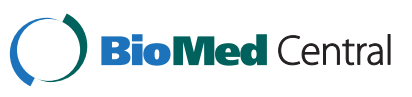


wealth of information on the molecular mechanisms of 3-BrPA have highlighted its potential as an effective agent for cancer treatment.

Several antineoplastic alkylating agents (e.g. cisplatin, oxaliplatin) have been known to interact with serum proteins upon systemic administration $[17,18]$. However, there is paucity of data indicating such interactions of 3-BrPA with any of the serum proteins. Although 3-BrPA differs considerably from the majority of alkylating agents in its mode of alkylation and its anticancer mechanism, any insight on the interaction of 3-BrPA with serum proteins would greatly improve our ability to use 3-BrPA systemically.

Previously we have shown that in the rabbit $\mathrm{Vx}-2$ liver tumor model, an IA therapeutic dose $(1.75 \mathrm{mM}$ concentration) of 3-BrPA did not affect normal liver parenchyma surrounding the tumor [16]. Notably, systemic administration of the IA therapeutic dose of 3-BrPA to tumor-bearing rabbits did not show any sign of toxicity [19]. Yet, the mechanism underlying the lack of systemic toxicity of 3-BrPA during systemic delivery remains unknown. In this report, we investigated the possible mechanism(s) associated with the lack of organ toxicity of systemically administered 3-BrPA using radiolabeled $\left({ }^{14} \mathrm{C}\right)-3-\mathrm{BrPA}$ in Sprague-Dawley rats.

\section{Results and discussion}

Data from the present study demonstrate that the glycolytic inhibitor, 3-BrPA selectively interacts with serum proteins. Further, it is also evident that such an interaction between 3-BrPA and serum proteins could explain the lack of toxicities when the drug is given systemically at least at the $1.75 \mathrm{mM}$ dose.

\section{Systemic administration of IA therapeutic dose of 3-BrPA shows no organ toxicity}

Tissue-autoradiography of rats subjected to systemic administration of ${ }^{14} \mathrm{C}-3$-BrPA showed strong radioactive ${ }^{14} \mathrm{C}$-signal in the tissue sections of organs such as heart, liver, kidney and lung, but not the brain (Figure 1A). Evidently, ${ }^{14} \mathrm{C}-3$-BrPA did not cross the blood-brain barrier, which in turn indicates that the neuronal cells could be protected from any toxicity. Remarkably, histopathological analysis of tissue sections that were positive for ${ }^{14} \mathrm{C}$-signal showed normal tissue architecture indicating no signs of toxicity or pathology as evident from $H \& E$ staining (Figure 1B). Further, TUNEL staining of the respective tissues from 3-BrPA treated rats showed no positive-staining (Figure $1 \mathrm{C}$ ), confirming the absence of any apoptosis. Since the tissues were not perfused it is likely that the ${ }^{14} \mathrm{C}$ signal observed in tissue sections were
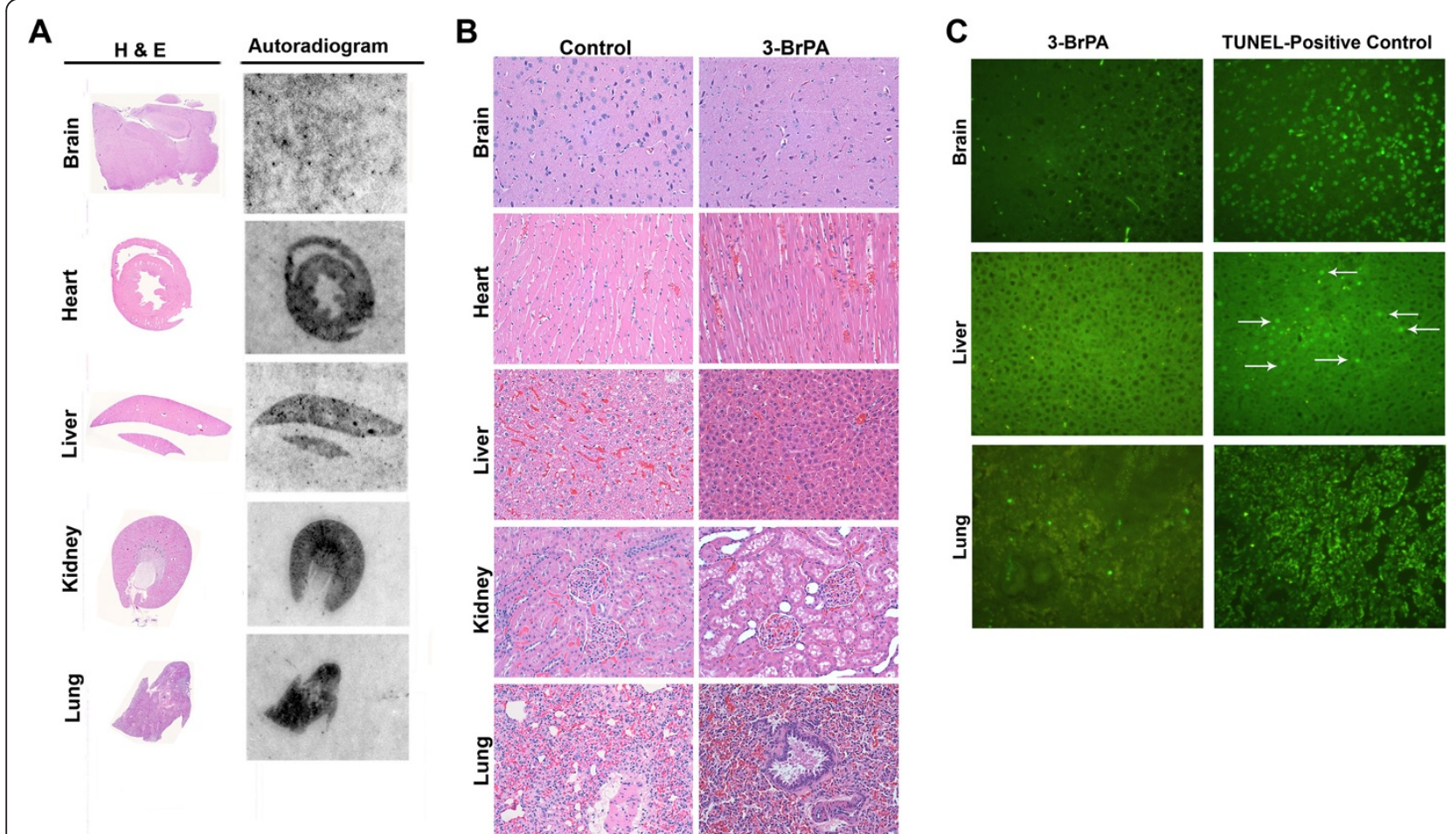

Figure 1 Distribution of ${ }^{14} \mathbf{C}-3-B r P A$ during systemic delivery. (A) Autoradiogram and corresponding $\mathrm{H}$ \& $\mathrm{E}$ staining of tissue sections showing radioactive signal in organs such as liver, lung, kidney and heart but not brain. (B) $\mathrm{H} \& \mathrm{E}$ staining showing normal tissue architecture in control and 3-BrPA dosed rat tissues. (C) TUNEL-assay showing absence of positive staining in 3-BrPA dosed rat tissues indicating absence of apoptosis. For comparison, TUNEL positive control slides have been included. 
from the serum which contained ${ }^{14} \mathrm{C}-3-\mathrm{BrPA}$. This is further supported by the gel-electrophoretic autoradiogram where serum proteins showed ${ }^{14} \mathrm{C}$ signal. Thus, the ${ }^{14} \mathrm{C}$ signal observed in tissue-autoradiography emanates from 3-BrPA that is non-toxic or non-reactive as it was neutralized or quenched by the interaction with serum proteins.

\section{Selective binding of ${ }^{14} \mathrm{C}-3$-BrPA with serum proteins}

Autoradiogram of rat serum samples resolved on SDSPAGE gel demonstrated that systemic administration of ${ }^{14} \mathrm{C}-3$-BrPA resulted in the selective incorporation of ${ }^{14} \mathrm{C}$ in rat serum proteins (Figure 2A, B). Interestingly, the pellet (containing erythrocytes and other particulates) did not show any ${ }^{14} \mathrm{C}$ incorporation even after $120 \mathrm{mi}-$ nutes of 3-BrPA administration. Based on the ${ }^{14} \mathrm{C}$ signal, the 3-BrPA binding has been found to be with the serum peptides of molecular range $\sim 50-60 \mathrm{kDa}$. Similarly, the autoradiogram of ${ }^{14} \mathrm{C}-3$-BrPA treated rat serum sample resolved on 2D-gel electrophoresis showed significant incorporation of ${ }^{14} \mathrm{C}$ selectively in two peptide spots, with strong and weak signals (Figure $3 \mathrm{~A}, \mathrm{~B}$ ). The autoradiogram signal of the peptide spots from the $2 \mathrm{D}$-gel also localized to the molecular range between $~ 50$ $60 \mathrm{kDa}$, as observed on the one-dimensional SDS-PAGE autoradiogram. Mass Spectrometry identification of the peptide spots corresponding to the strong and weak signals were found to be peptides of alpha- 1 antitrypsin ( $\alpha 1-\mathrm{AT}$ ) and an albuminoid-family, respectively (Figure 3C, D).

In another experiment, the $\mathrm{UV}-\mathrm{V}$ is spectral analysis $(180 \mathrm{~nm}$ to $800 \mathrm{~nm})$ of mouse serum samples incubated with 3-BrPA ex vivo, demonstrated a dose-dependent increase in the absorption maxima of certain serum components at 412, 538 and $572 \mathrm{~nm}$, but not at 200-204 nm (the absorption maxima of native 3-BrPA) (Additional file 1: Figure S2). The spectral data refer to the total serum components that may include proteins, non-proteinaceous components, small molecules such as glutathione, cysteine, $\mathrm{NAD} / \mathrm{NADH}$ etc. The objective of the spectral analysis was to demonstrate that 3-BrPA treatment-dependent changes were prominent for the serum components, which was depicted by the pronounced changes at wavelengths such as 412,538 and $572 \mathrm{~nm}$. The wavelength spectra between 200-204 nm showed the peak absorbance of aqueous 3-BrPA solution that was used as the control. In the serum samples, we did not see any peak at 200-204 nm, which implied that there was no free-3-BrPA present in the serum. Further investigations showed that free-3-BrPA in vivo was not detectable by HPLC/mass spectrophotometer even after dose escalation (not shown). The absence of free-3-BrPA in vivo as early as $2-3$ minutes after systemic administration also provided proof for the immediate reactivity or neutralization of 3-BrPA in serum.

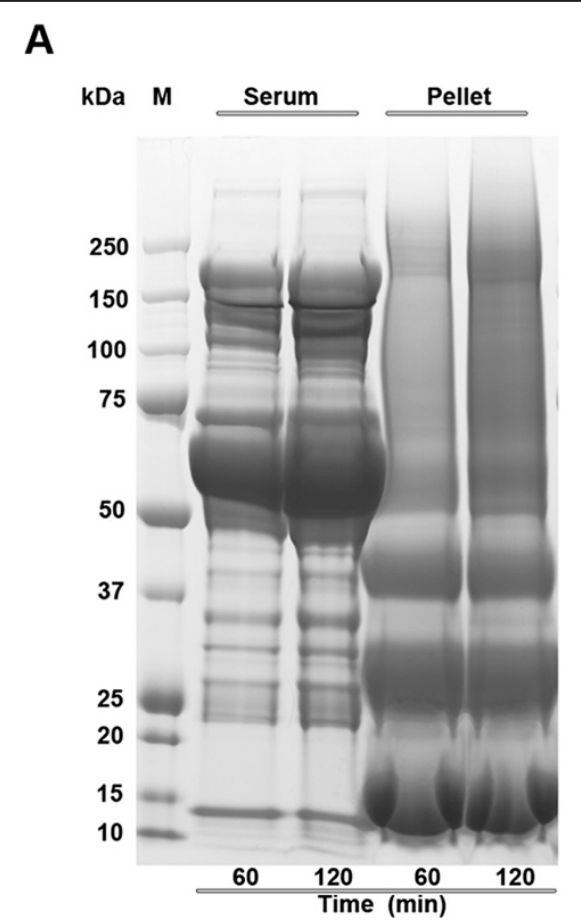

B

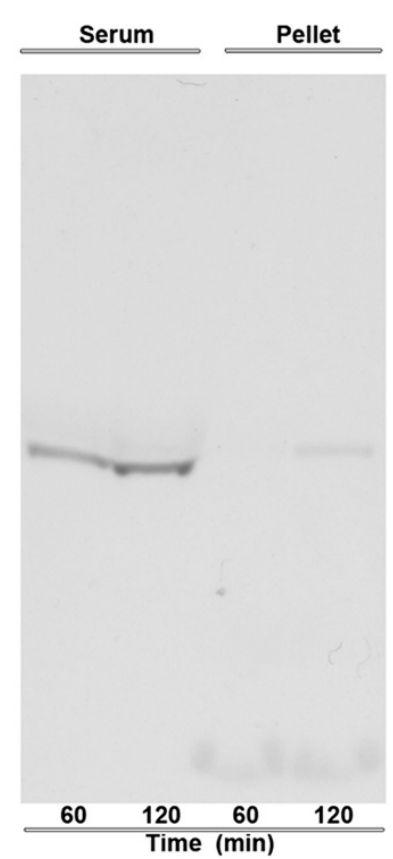

Figure 2 Selective binding of ${ }^{14} \mathrm{C}-3$-BrPA with rat serum proteins. (A) Coomassie stained SDS-PAGE gel showing the protein profile of serum and pellet of ${ }^{14} \mathrm{C}-3-\mathrm{BrPA}$ dosed rat. (B) A corresponding autoradiogram showing time-dependent increase in autoradiogram signal in the serum, at $~ 50-60 \mathrm{kDa}$. Serum obtained from blood collected $60 \mathrm{~min}$ or 120 minutes after the 3-BrPA infusion indicate a time dependent increase in the amount of ${ }^{14} \mathrm{C}$ incorporation. 


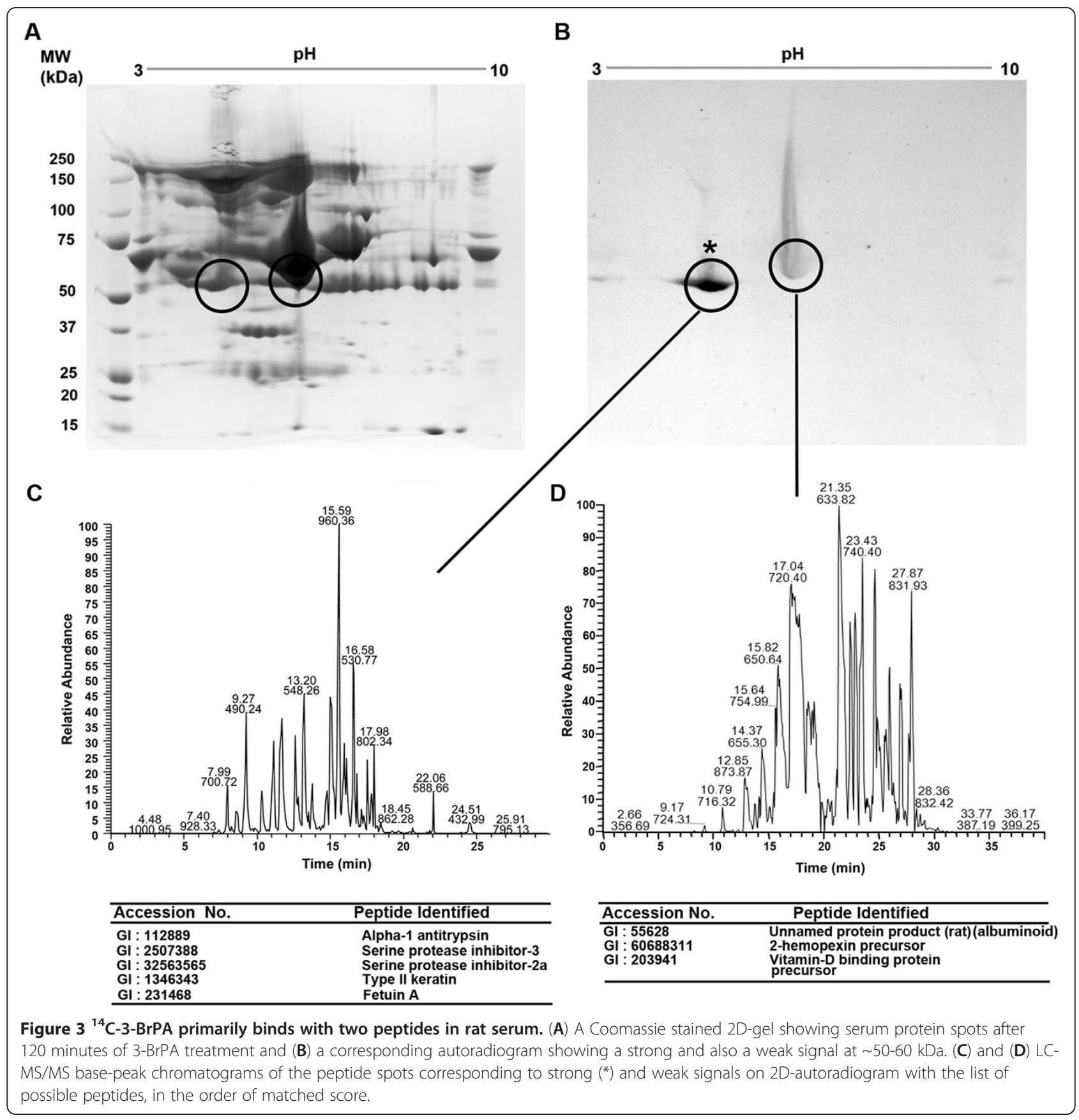

Taken together, the data obtained from proteomic and spectral analyses validate the interaction of 3-BrPA with serum proteins. Although the interaction of anticancer agents such as metallo-drugs with albumin has already been demonstrated $[17,18]$, binding of such agents to a1-AT has not yet been reported, especially with any anti-glycolytic agents. This report is the first to indicate a possible interaction between an anticancer (alkylating) agent (3-BrPA) and $\alpha 1-\mathrm{AT}$. $\alpha 1-\mathrm{AT}$ has been known to be an inhibitor of neutrophil elastase, and this inhibition is required to prevent the enzymatic-degradation of elastin (in lungs). Hence, further studies are required to characterize the impact of 3-BrPA-binding on the inhibitory function of $\alpha 1$-AT.

\section{Conclusion}

Given the promising pre-clinical results on the therapeutic efficacy and mechanism(s) of action of 3-BrPA, the potential exists for translation into the clinic. As a result, it is imperative to understand the possible toxic side effect of 3-BrPA, especially if systemic administration is being contemplated. Our previous report showed 
that in the rabbit Vx-2 tumor model a dose that was effective given IA did not cause any significant systemic toxicity [19]. As our findings demonstrate the interaction of 3-BrPA with serum proteins, it is likely that the particular interacting 3-BrPA molecule will no longer be available for further alkylation or toxicity. Further, owing to the irreversible alkylating property of 3-BrPA, it is unlikely that the 3-BrPA might be released from these proteins at later stages to contribute any toxicity.

Thus, this report provides an explanation for the apparent lack of systemic toxicity, which could prove extremely useful when considering the optimization of systemic therapy with 3-BrPA.

\section{Methods}

\section{In vivo (systemic) infusion of 3-BrPA to rats}

All animals were housed at The Johns Hopkins University Animal Facility, and handled according to the guidelines of $\mathrm{NIH}$ and protocols approved by the Institutional Animal Care and Use Committee. Male Sprague Dawley rats (400 to 500 grams body weight) were purchased from Charles River Laboratory (USA) and maintained on automated 12-hour dark/light cycles and allowed access to food and water ad libitum.

The radio- $\left({ }^{14} \mathrm{C}\right)$-labeled 3 -BrPA was synthesized as described previously [19]. Rats were subjected to catheterization procedure (as described in "Additional file 1 ") in order to infuse $\left({ }^{14} \mathrm{C}\right)-3-\mathrm{BrPA}$ and to draw blood at different time intervals. Three rats were used for this preliminary study. The experiments were initiated by the systemic administration of a single dose of $\left({ }^{14} \mathrm{C}\right)-3$ $\mathrm{BrPA}(700 \mu \mathrm{l}$ of $1.75 \mathrm{mM}$ solution) via the femoral vein (Additional file 1: Figure S1). The volume of the dose was determined based on the principle that the administered drug-volume not to exceed $3.5 \%$ (i.e. the median of $2-5 \%$ ) of the total rat-blood volume. Blood samples were collected via the carotid artery at pre-treatment and different time points after $\left({ }^{14} \mathrm{C}\right)-3$-BrPA infusion. Blood samples were collected in $1.5 \mathrm{~mL}$ eppendorf tubes, allowed to stand at room temperature for 20-30 minutes to form serum separation, followed by centrifugation at $1200 \mathrm{rpm}$ for 20 minutes at $4^{\circ} \mathrm{C}$. The clear serumsupernatants were stored at or below $-20^{\circ} \mathrm{C}$ until further analysis. The tissues were harvested at the end of blood collection (120 minutes) by sacrificing the experimental animal, and used for histopathology and autoradiographic analysis.

\section{Histopathology and tissue autoradiography}

For histology, tissues from rat organs such as heart, lung, liver, kidney and brain were routinely fixed in phosphatebuffered 10\% formalin (Polysciences Co., Warrington, PA), dehydrated by graded ethanol, embedded in Paraplast Plus wax (McCormick Scientific), sectioned at 5 microns, mounted on slides and oven dried and deparaffinized. The tissue sections were subjected to Hematoxylin and Eosin (H\&E) staining as described earlier [14] and viewed under a light microscope. Apoptosis was investigated using terminal deoxynucleotidyl transferase dUTP nick-end labeling (TUNEL) assay kit (Millipore Corp., Bedford, MA) following the manufacturer's protocol. Finally, tissue sections were covered with cover slips and mounted with Prolong Gold Antifade Reagent (Invitrogen) and allowed to dry in the dark. The slides were viewed under fluorescent microscopy and the images were captured using Nikon Coolpix digital camera (Nikon Instruments, Inc., Melville, NY). Tissue sections from each rat were used for histopathology analysis.

For tissue autoradiography, the unstained histology slides derived from ${ }^{14} \mathrm{C}-3-\mathrm{BrPA}$ infused rat organs were placed in a large $\mathrm{x}$-ray cassette with intensifying screens, and exposed to $\mathrm{x}$-ray film for 30 days at $-80^{\circ} \mathrm{C}$ followed by film developing.

\section{SDS-PAGE, 2D gel electrophoresis and autoradiography}

The SDS-PAGE as well as 2D gel electrophoresis was performed as described earlier [6]. In brief, serum protein concentration was determined using a 2D-Quant kit (GE- Healthcare, Piscataway, NJ). One-dimensional electrophoresis (SDS-PAGE) was performed using NuPAGE Bis-Tris 4-12\% gels followed by colloidal Coomassie blue staining [20]. The samples for 2D gel electrophoresis were cleaned-up using a 2D-Clean-up kit (GE-Healthcare). Isoelectric focusing was performed using Immobiline ${ }^{\text {тM }}$ dry gel strips of linear pI (isoelectric point) range $3-10,7 \mathrm{~cm}$ (GE-Healthcare). The focused gel strips were subjected to second dimensional separation using NuPAGE BisTris 4-12\% Zoom gels (Invitrogen, Grand Island, NY), and subjected to colloidal Coomassie blue staining. Serum samples obtained from ${ }^{14} \mathrm{C}-3-\mathrm{BrPA}$ infused rats were resolved on SDS-PAGE and 2D gels, and subsequently incubated with "Amplify" solution (GEHealthcare) prior to vacuum drying and exposed to X-ray film (GE-Healthcare) to obtain the images of autoradiogram. Only the authorized personnel handled all procedures involving ${ }^{14} \mathrm{C}-3-\mathrm{BrPA}$, and appropriate radioactive decontaminations/containments were followed strictly according to the Johns Hopkins Radiation Safety Rules and Regulations.

\section{Protein identification by liquid chromatography-tandem mass spectrometry (LC-MS/MS)}

Protein spots from 2D-gels were proteolyzed with trypsin as described previously [21]. Digested peptides were extracted and subjected to vacuum drying in a Speedvac, followed by reconstitution in $5 \mu \mathrm{L}$ of $2 \%$ acetonitrile/ $0.1 \%$ formic acid, for further analysis by liquid chromatography/tandem mass spectrometry (LC-MS/MS) using 
LTQ Orbitrap Velos (2) MS (Thermo Fisher Scientific, www.thermofisher.com).

Peptides were loaded on a $75 \mu \mathrm{m} \times 2.5 \mathrm{~cm} \quad \mathrm{C} 18$ (YMC*GEL ODS-A $12 \mu \mathrm{nm} \mathrm{S}-10 \mu \mathrm{m}$ ) trap at $600 \mathrm{~nL} /$ min $0.1 \%$ formic acid (solvent A) and fractionated at $300 \mathrm{~nL} / \mathrm{min}$ on a $75 \mu \mathrm{m} \times 100 \mathrm{~mm}$ Magic C18 AQ $5 \mu \mathrm{m}$ reverse-phase column $(5 \mu \mathrm{m}, 120 \AA$, Microm Bioresources, www.michrom.com) using a 3-10\% solvent B (90\% acetonitrile in $0.1 \%$ formic acid) gradient over $40 \mathrm{~min}$. Eluting peptides were sprayed into an LTQ Orbitrap Velos mass spectrometer (ThermoScientific, www.thermo.com/ orbitrap) through $1 \mu \mathrm{m}$ emitter tip (New Objective, www. newobjective.com) at $2.0 \mathrm{kV}$. Survey scans (full ms) were acquired within $350-1700 \mathrm{~m} / \mathrm{z}$ with up to 10 peptide masses (precursor ions) individually isolated at IW1.9 Da, and fragmented (MS/MS) using HCD 35 activation collision energy. Precursor and the fragment ions were analyzed at resolution 30,000 and 15,000 , respectively. Dynamic exclusion of $30 \mathrm{~s}$, repeat count 1 , MIPS (monoisotopic ion precursor selection) "on", m/z option "off", lock mass "on" (silocsane $371 \mathrm{Da}$ ) were used.

For data analysis, tandem mass spectra were extracted, charge state deconvoluted and deisotoped by Proteome Discoverer (v1.3 Thermo Fisher Scientific). All MS/MS spectra were analyzed with Mascot v.2.2 Matrix Science, London, UK (www.matrixscience.com) using the NCBI 167nr Database, Rattus species with acquired raw MS/ MS data, trypsin as enzyme, missed cleavage 1, precursor mass tolerance $10 \mathrm{ppm}$, fragment mass tolerance $0.02 \mathrm{Da}, \mathrm{y}, \mathrm{b}$ ions, and oxidation on methionine as variable modifications. For each sample, Mascot search result *.dat files for nodes with/without extract were processed in Scaffold (www.proteomesoftware.com) combined as MUDPIT experiment to validate protein and peptide identifications.

\section{Additional file}

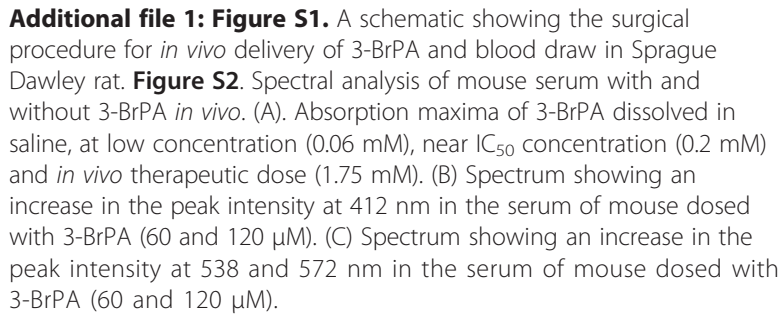

\section{Abbreviations}

3-BrPA: 3-bromopyruvate; LC-MS/MS: Liquid chromatography-tandem mass spectrometry; a1-AT: Alpha1 antitrypsin; 2D: gel electrophoresis: Twodimensional gel electrophoresis; TUNEL: Terminal deoxynucleotidyl transferase dUTP nick-end labeling.

\section{Competing interests}

Dr. Geschwind is the founder of Presciencelabs LLC, a biotech firm currently developing 3-BrPA for clinical use in liver cancer.

\section{Authors' contributions}

RK carried out the experiments such as immunohistochemical staining, 2D gel electrophoresis, spectroscopy analysis and drafted the manuscript. JG performed the conception and participated in the experimental design, and edited the manuscript. PR performed in vivo studies. TB and RC carried out the mass spectrometry analysis of $2 \mathrm{D}$ gel spots and data interpretation. SG-K conceived and designed the experiments, performed tissue and gel autoradiography, and drafted the manuscript. All authors read and approved the final manuscript.

\section{Acknowledgements}

This work was supported by the Abdulrahman Abdulmalik Research Fund (J.F.G) and the Charles Wallace Pratt Research Fund (J.F.G). The LC-MS/MS experiments were supported by the Mass Spectrometry and Proteomics

Core Facility of the Sidney Kimmel Comprehensive Cancer Center at Johns Hopkins (NIH grants P30 CA006973).

\section{Author details}

${ }^{1}$ Russell H. Morgan Department of Radiology and Radiological Sciences, Johns Hopkins University School of Medicine, 600 N. Wolfe Street, Baltimore, MD 21287, USA. ${ }^{2}$ Mass Spectrometry and Proteomics Facility, Johns Hopkins University School of Medicine, 733, N. Broadway Street, Baltimore, MD 21205, USA.

Received: 28 February 2013 Accepted: 3 July 2013

Published: 17 July 2013

\section{References}

1. Vander Heiden MG: Targeting cancer metabolism: a therapeutic window opens. Nat Rev Drug Discov 2011, 10(9):671-684.

2. Dang CV, Hamaker M, Sun P, Le A, Gao P: Therapeutic targeting of cancer cell metabolism. J Mol Med 2011, 89(3):205-212.

3. Hamanaka RB, Chandel NS: Targeting glucose metabolism for cancer therapy. J Exp Med 2012, 209(2):211-215.

4. Geschwind JF, Georgiades CS, Ko YH, Pedersen PL: Recently elucidated energy catabolism pathways provide opportunities for novel treatments in hepatocellular carcinoma. Expert Rev Anticancer Ther 2004, 4(3):449-457.

5. Ganapathy-Kanniappan S, Vali M, Kunjithapatham R, Buijs M, Syed LH, Rao PP, Ota S, Kwak BK, Loffroy R, Geschwind JF: 3-Bromopyruvate: a New targeted antiglycolytic agent and a promise for cancer therapy. Curr Pharm Biotechnol 2010, 11(5):510-517.

6. Ganapathy-Kanniappan S, Geschwind JF, Kunjithapatham R, Buijs M, Vossen JA, Tchernyshyov I, Cole RN, Syed LH, Rao PP, Ota S, Vali M: Glyceraldehyde-3phosphate dehydrogenase (GAPDH) is pyruvylated during 3-bromopyruvate mediated cancer cell death. Anticancer Res 2009, 29(12):4909-4918.

7. da Silva PAP, El-Bacha T, Kyaw N, Dos Santos RS, Da-Silva WS, Almeida FC, Da Poian AT, Galina A: Inhibition of energy-producing pathways of HepG2 cells by 3-bromopyruvate. Biochem J 2009, 417(3):717-726.

8. Ganapathy-Kanniappan S, Geschwind JF, Kunjithapatham R, Buijs M, Syed LH, Rao PP, Ota S, Kwak BK, Loffroy R, Vali M: 3-Bromopyruvate induces endoplasmic reticulum stress, overcomes autophagy and causes apoptosis in human HCC cell lines. Anticancer Res 2010, 30(3):923-935.

9. Ko YH, Pedersen PL, Geschwind JF: Glucose catabolism in the rabbit VX2 tumor model for liver cancer: characterization and targeting hexokinase. Cancer Lett 2001, 173(1):83-91.

10. Geschwind JF, Ko YH, Torbenson MS, Magee C, Pedersen PL: Novel therapy for liver cancer: direct intraarterial injection of a potent inhibitor of ATP production. Cancer Res 2002, 62(14):3909-3913.

11. Zhang X, Varin E, Briand M, Allouche S, Heutte N, Schwartz L, Poulain L, Icard P: Novel therapy for malignant pleural mesothelioma based on anti-energetic effect: an experimental study using 3-Bromopyruvate on nude mice. Anticancer Res 2009, 29(4):1443-1448.

12. Hulleman E, Kazemier KM, Holleman A, VanderWeele DJ, Rudin CM, Broekhuis MJ, Evans WE, Pieters R, Den Boer ML: Inhibition of glycolysis modulates prednisolone resistance in acute lymphoblastic leukemia cells. Blood 2009, 113(9):2014-2021.

13. Bhardwaj V, Rizvi N, Lai MB, Lai JC, Bhushan A: Glycolytic enzyme inhibitors affect pancreatic cancer survival by modulating its signaling and energetics. Anticancer Res 2010, 30(3):743-749.

14. Ganapathy-Kanniappan S, Kunjithapatham R, Torbenson MS, Rao PP, Carson KA, Buijs M, Vali M, Geschwind JF: Human hepatocellular carcinoma in a mouse 
model: assessment of tumor response to percutaneous ablation by using glyceraldehyde-3-phosphate dehydrogenase antagonists. Radiology 2012, 262(3):834-845.

15. Birsoy K, Wang T, Possemato R, Yilmaz OH, Koch CE, Chen WW, Hutchins AW, Gultekin Y, Peterson TR, Carette JE, Brummelkamp TR, Clish CB, Sabatini DM: MCT1-mediated transport of a toxic molecule is an effective strategy for targeting glycolytic tumors. Nat Genet 2013, 45(1):104-108.

16. Vali M, Liapi E, Kowalski J, Hong K, Khwaja A, Torbenson MS, Georgiades C, Geschwind JF: Intraarterial therapy with a new potent inhibitor of tumor metabolism (3-bromopyruvate): identification of therapeutic dose and method of injection in an animal model of liver cancer. J Vasc Interv Radiol 2007, 18(1 Pt 1):95-101.

17. Lemma T, Pawliszyn J: Human serum albumin interaction with oxaliplatin studied by capillary isoelectric focusing with the whole column imaging detection and spectroscopic method. J Pharm Biomed Anal 2009, 50(4):570-575.

18. Groessl M, Terenghi M, Casini A, Elviri L, Lobinski R, Dyson PJ: Reactivity of anticancer metallodrugs with serum proteins: new insights from size exclusion chromatography-ICP-MS and ESI-MS. J Anal At Spectrom 2010, 25(3):305-313

19. Vali M, Vossen JA, Buijs M, Engles JM, Liapi E, Ventura VP, Khwaja A, Acha-Ngwodo O, Shanmugasundaram G, Syed L, Wahl RL, Geschwind JF: Targeting of VX2 rabbit liver tumor by selective delivery of 3-bromopyruvate: a biodistribution and survival study. J Pharmacol Exp Ther 2008, 327(1):32-37.

20. Neuhoff $V$, Arold N, Taube D, Ehrhardt W: Improved staining of proteins in polyacrylamide gels including isoelectric focusing gels with clear background at nanogram sensitivity using Coomassie Brilliant Blue G-250 and R-250. Electrophoresis 1988, 9(6):255-262.

21. Shevchenko A, Wilm M, Vorm O, Mann M: Mass spectrometric sequencing of proteins silver-stained polyacrylamide gels. Anal Chem 1996, 68(5):850-858

doi:10.1186/1756-0500-6-277

Cite this article as: Kunjithapatham et al: Systemic administration of 3-bromopyruvate reveals its interaction with serum proteins in a rat model. BMC Research Notes 2013 6:277.

\section{Submit your next manuscript to BioMed Central and take full advantage of:}

- Convenient online submission

- Thorough peer review

- No space constraints or color figure charges

- Immediate publication on acceptance

- Inclusion in PubMed, CAS, Scopus and Google Scholar

- Research which is freely available for redistribution 